\section{A experiência da música e as escutas contemporâneas}

\author{
RESUMO \\ Este artigo propõe uma reflexão sobre a dimensão da experiência \\ da escuta contemporânea, buscando examinar os seus estatutos a \\ partir dos escopos que a mídia, a tecnologia e a cultura operam mu- \\ tuamente na construção perceptiva da nossa experiência sônica e \\ vice-versa. Presidem então a esta análise tanto a atenção acerca da \\ dimensão cultural como sobre a perceptual da experiência estética \\ no campo sonoro. Os principais tópicos de abordagem consistem \\ na obsenvação de pontos de partida perceptuais nos quais o ouvinte \\ hipoteticamente se apóia para realizar sua experiência habitual com \\ a música e, a seguir, considerar o pensamento de autores como John \\ Cage, Pierre Schaeffer, Steve Reich, Brian Eno e Silvio Ferraz acerca \\ das modalidades de escuta contemporânea.
}

\section{RESUMO}

The purpose of this article is to reflect upon contemporary music listening taking into account the points of view that media, technology and culture impose on the percetual construction of ouro sonic experience and vice versa. This analysis considers ideas of authors like John Cage, Pierre Schaeffer, Siteve Reich, Brian Eno and Silvio Ferra, according to contemporary listening modalities.

\author{
PALAVRAS-CHAVE \\ - Mediação (Mediation) \\ - Música (Music) \\ - Experiência estética (Aesthetic experience)
}

\footnotetext{
Rodrigo Fonseca e Rodrigues

Faculdade Metropolitana de Belo Horizonte/MG
}

Nesses vinte e cinco séculos, de Platão a John Cage, as reflexões acerca das instâncias do belo e da arte musical transitaram entre múltiplos horizontes de investigação, marcados também pela submissão às diversas escolas de pensamento: da "música das esferas" à arte da sensualidade e da indisciplina, do culto ao hedonismo ao rigor do juízo crítico, da imanência à transcendência, do fetiche à utopia, das rígidas estruturas sistêmicas às probabilidades informacionais. Transitaram pelas esferas do trágico e do patético, do apolíneo e do dionisíaco, do ethos e da metafísica, pela pesquisa sistematizada do seu desenvolvimento gramatical e pela atenção, esta mais recente, sobre as dimensões do seu reconhecimento e das suas modalidades de recepção.

A reflexão que este artigo propõe é a de atualizar a discussão a respeito da experiência contemporânea da música, em suas diversas modalidades alternativas de invenção e escuta. Para um melhor acompanhamento do seu desenho, é importante apontar as principais balizas que o orientam, como a compreensão das nossas potencialidades da percepção sonora e dos condicionamentos e conotações culturais relacionados na escuta. Tal abordagem visa a demonstrar como a análise da apreensão musical contemporânea merece ser repensada, para se entender a experiência sonora como parte do descortinar de novas dimensões comunicativas que ampliam as nossas prerrogativas de escuta.

Sabemosoquantoagravação, areprodução e a difusão mediática da música expandiram as oportunidades para a sua fruição, mas também as dessacralizaram como formas de contemplação tradicionais. Também passamos a experienciar uma audição desritualizada, desprendida dos espaços de confinamento fruitivo, pagando com a dispersão da consciência diante da massiva afluência sonora. Podemos ouvir, como e quando quisermos, uma mesma peça musical, milhares de vezes e também acionamos ou interrompemos, com um simples zapping, qualquer execução sonora, bem como podemos fazer outras tarefas cotidianas enquanto escutamos música: durante as leituras, enquanto trabalhamos no computador 
ou navegamos na rede, nos momentos de introspecção, no carro, em aviões, nas salas de espera, elevadores, estações e supermercados, na rua, enquanto dormimos, na hora do sexo, do banho, do passeio, da ginástica, em festas, coquetéis, cerimônias cívicas ou religiosas, boates, festivais, shows, concertos, bares, etc. A inflação dos signos sonoros e da exposição excessiva a que somosimpingidos, em quaisquer ambientes e situações sociais, contribuiu para dissolver o culto e a demanda ritualizada de concentração da experiência tradicional, com o preço da depreciação de seu antigo impacto "aurático" sobre a percepção.

Em tais contextos, parece haver elementos decisórios específicos recorrentes nas formas contemporâneas de pensar, realizar, compartilhar e ouvir música, num tecido plural de relações que se influenciam mutuamente. Os princípios de tal experiência sonora advêm de: 1) condições mediatizadas nos circuitos de bens de consumo musicais; 2) recursos tecnológicos que propulsionam novos meios de se gerar a matéria sonora e forjarem daí novos materiais expressivos; 3)diferentes potencialidades de escuta estimuladas pelas novas formas de acesso musical; 4) posturas estéticas que, ao possibilitar alternativas para a experiência sonora, fazem emergir um novo tipo de ouvinte mais atento a tais procedimentos poéticos; 5) ma escuta que fomenta a poética dos artistas envolvidos com as práticas criativas renovadas.

Em meio a tantas expectativas difusas nas quais mergulham os ouvintes contemporâneos, consideramos, doravante, os estatutos de conotação cultural que condicionaram a escuta a uma atividade repertoriada, bem como as alternativas para ultrapassá-la, apontadas por John Cage. Mais à frente, abordamos as propostas de uma escuta concreta, nãoabstrata, por Pierre Schaeffer, defensor da escuta "acusmática" para se descondicionarem os sons das suas conotações simbólicas. Passamos a apresentar, em seguida, as prerrogativas da escuta minimalista de Steve Reich para estimular a percepção sobre as nuanças materiais do som, seguidas pelo pensamento de Brian Eno a respeito das modalidades da escuta propulsionadas pela ambient music e apresentamos as alternativas para uma escuta textural e heterogênea, advogada por Sílvio Ferraz. Antes, porém, é importante salientar alguns aspectos culturais que modelam a atividade e as expectativas relacionadas com a experiência perceptual da música ocidental.

A importância que atribuímos a atitudes e reflexões desconstrutoras enunciadas pelo poeta dos sons que foi John Cage, a partir de seus textos e da sua primeira peça eletroacústica (Imaginary Landscapes), criada em 1939, resulta do fato de ele pressentir, assim como outros jovens artistas, as obscuridades ontológicas em que se viciara a cultura artística da chamada civilização ocidental. Há, na seguinte afirmação de Cage, mais do que um dos muitos chistes bem-humorados do polêmico compositor americano:

Eu aprendi que os intervalos possuem significados, que eles não são propriamente sons, mas implicam suas progressões um som não realmente apresentado aos ouvidos, mas à mente. Toda questão aqui é muito intelectual: fazer pensar em sons que não estão propriamente presentes nos ouvidos. A separação entre ouvido e mente estragou os sons. É preciso liberar os sons das idéias abstratas sobre eles ${ }^{1}$.

Na concepção de Cage, tudo é atacado, desconstruído, dos edifícios ideológicos à armadura sagrada da sintaxe. Ele reivindicava o fim das premissas culturais do concerto clássico como um culto ritualístico da experiência estética e defendeu, com toda a ironia e bom humor, maior liberdade à escuta, para que saibamos não apenas ouvir a elite dos sons musicais, mas também apreciar os ruídos diários:

Uma das coisas que sabemos hoje em dia é que algo que acontece pode ser experienciado por meio da técnica eletrônica como outra coisa. Por exemplo, a gente entrando e saindo de elevadores e os elevadores andando de um andar para outro: essa informação pode ativar circuitos que levam aos nossos ouvidos uma concatenação de sons. Talvez você não concordasse que o que ouviu era música. Mas, nesse caso, outra transformação teria ocorrido: o quevocê ouviulevou asuamente a repetir definições de arte e música que se encontram em dicionários obsoletos².

Cage convocava as pessoas para que ultrapassassem as molduras culturais para algo mais além do uso obediente à sintaxe musical. Finalmente, o artista sugere que é preciso 
urgentemente descondicionar-se da expectativa auditiva habitual, e estar atento não apenas à fraseologia musical (hierarquia que pressupõe sempre algo acabado), mas a toda e qualquer atividade dos sons.

Pierre Schaeffer, quando expôs a problemática das impurezas simbólicas que permeiam a escuta da música habitual, sugeriu um tipo de escuta "acusmática", proposta anteriormente por seu colega François Bayle. Nesta modalidade da escuta, um som é ouvido sem que se revele a fonte que o produziu, ou seja, sem qualquer relação do som com o que é visível, táctil ou mensurável. A experiência da escuta acusmática mostra que grande parte daquilo que acreditamos estar ouvindo é na verdade resultante da experiência visual associada à audição, uma escuta quase automática na qual a cadeia de signos disparada pelo objeto sonoro transforma-se em mensagens complexas. Por esta razão, Schaeffer propõe uma escuta que se atenha unicamente à sonoridade mesma.

Tal escuta material do som que visa a bloquear o conceito e a representação foi expandida pelos compositores minimalistas nos anos sessenta e setenta, período que redimensionou, para muitos, os pressupostos da escuta musical. No minimalismo, a escuta não é predeterminada com relação a um conceito fixo, mas sim deixada à capacidade das faculdades perceptivas do ouvinte de descobrir nuanças do som em si, de localizar pequenos detalhes timbrísticos que se desprendem do continuum sonoro. A escuta é chamada a perceber as resultantes espectrais, os sons residuais, os batimentos harmônicos, as melodias e ritmos parasitas, a repetição nua da matéria e a tatilidade do tempo pulsante. A música minimal permite e dá tempo ao ouvinte de penetrar no objeto, a fim de descobrir a diferenciação gradual por acréscimos e subtrações sutis de elementos.

Ao expor o ouvinte a jogos reiterativos de durações extremamente longas aos quais ele não está acostumado, o minimalismo ignora a pressão do tempo e redefine a escuta, agora acionada na intensidade perceptiva de cada momento. Na escuta minimal, tanto o conceito quanto a memória parecem ineficazes em representar todos os seus aspectos e os seus movimentos texturais. Nesta modalidade da escuta, como afirma o autor Sílvio Ferraz, a memória não é chamada a atuar, "pois não se trata de relacionar um elemento a outro, mas sim de descobrir e deixar-se levar pela diversidade material que é gerada pela reiteração de padrões sonoros, não abarcável pela representação"3.

O minimalismo contém elementos estáticos que o ouvinte não notaria, acostumado a esperar pelas mudanças e pelo drama musical. Mas, apesar do material ser aparentemente limitado, o montante de atividade acionada impulsiona o ouvinte para uma situação perceptiva complexa. O princípio da reiteração do material sonoro desobriga a memória de vasculhar no passado próximo, à procura dos elementos formais de construção de um sentido musical. No processo da escuta minimal somos motivados a ativar as micropercepções presentes numa escuta intensiva. Focaliza-se a matéria sonora, nas alternativas formais de sua exposição, nas suas diferentes paradas e começos, uma vez que a reiteração e o fluxo são dirigidos a um foco constante, na escuta das fases que emergem, de modos diferentes, a cada ciclo.

Uma outra possibilidade de experiência sonora anteriormente concebida pelas poéticas de Erik Satie e John Cage é aperfeiçoada por Brian Eno na sua ambient music. De fato, Eno começara a perceber que a partir dos contextos espaço-temporais da escuta cotidiana, a centenária tecnologia voltada para a produção e reprodução musical permitia continuamente a criação de novos ambientes e hábitos de escuta. Perscrutou o quanto podia uma nova modalidade de se fazer e apreender música, relacionando-se com ela como se estivesse compartilhando o espaço com uma espécie de aquarela acústica ou de escultura sônica.

Parece que Eno começou a perceber as transformações que ocorriam nos hábitos auditivos da época, não apenas no plano tecnológico dosaparelhos eespaços domésticos de escuta (como no surgimento do toca-fitas, rádios e toca-discos portáteis), mas também nas lojas de discos que proliferavam e ainda pela penetração da música popular norte-americana, desde os anos cinqüenta, no mercado da Inglaterra. O sentido de estranheza que essa nova música propiciava vinha justamente de uma descontextualização cultural da sua escuta.

Perpassava pelos princípios poéticos de Brian Eno o intento de colorir a atmosfera, rodear o ouvinte, criar um senso de espacialidade e profundidade que permitisse também ao ouvinte "mover-se" por entre espaços sônicos alternativos. A composição "ambient" de Eno, além da construção de atmosferas criteriosas, permite ser ouvida em diferentes espaços da 
vida cotidiana, com diferentes expectativas, tal como antes começaram a imaginar Satie, Varèse e Cage. O princípio da "ambient music" visava, em princípio, a redimensionar o espaço e o modo da escuta mediatizada, a fim de permitir ao ouvinte acoplar a sonoridade como um suplemento ao meio ambiente íntimo da escuta privada.

Para esse non-musician assumido, ouvir música é algo como capturar parte de um processo infinito. Por isso ele concebe a presença dos eventos acústicos como algo que simplesmente flui, um infinito continuum no qual nós entramos ou o abandonamos. O estatuto da compreensão auditiva sofre uma mutação, ou seja, é outro. E diverso é também o alcance da escuta na modulação livre da percepção, entre nuanças, planos e texturas, espectros sônicos e extratos acústicos permeáveis.

A ambient music também não exige aquela forma perceptiva proposta pela teoria da Gestalt, feita de relações entre frente e fundo. $O$ ouvinte pode focalizar muitas coisas, alcançando muito mais do quea representação eaidéiamusical. Ele pode perceber a música sob uma variedade de perspectivas que revela diferentes estratégias de escuta. O "ambient" é, de outro ponto de vista, um meio diferente de explorar, em sua experiência, os aspectos verticais na composição do som, os seus espectros harmônicos, a sua qualidade timbrística. Enquanto que na música tradicional o timbre é acessório, na ambient music a sua dimensão é estrutural. As informações sonoras, tal como se dá no minimalismo, não requerem a aptidão da memória treinada e conotada pela cultura da música tradicional na tarefa de enfeixar e apartar lampejos do passado e amarrá-los numa suposta estrutura mais profunda.

Novas alternativas para uma escuta contemporânea condizente com as formas de composição engendradas nas últimas décadas foram coerentemente aventadas por Sílvio Ferraz. Através do vocabulário conceitual criado por Gilles Deleuze, ele dá especificidade ao pensamento deleuziano ao aplicar detidamente o seu funcionamento no plano musical, quando discute particularmente o conceito de ritornelo ${ }^{4}$.

$\mathrm{Na}$ concepção de Sílvio Ferraz, há três categorias aventadas através das quais a escuta pode configurar-se: a gestual, a figural e a textural. O gesto atribui aos sons uma rede complexa de significados; a figura atua como a escuta das relações e funções, fornecendo pontos de referência para a memória; e a textura diz respeito às nuanças sonoras inabarcáveis pela memória e pela representação.

A primeiraalternativaéaescutaqueprivilegia o gesto, na qual os sons não são elementos em si, mas sim a sua tradução, a representação sonora de elementos extramusicais e afetivos. Ela ocorre quando a experiência perceptiva se limita a regras determinadas a priori. A segunda categoria da escuta preestabelece um quadro de símbolos atribuídos a cada textura sonora, o aspecto simbólico da música como função estrutural, sejam esses símbolos semânticos ou sintáticos. A terceira, informal e não-estrutural, é despida de um ponto fixo ou permanente e concebida como uma mônada indivisível, porém heterogênea, que se articula nos espaços potenciais do retorno do diferente, em suas potencialidades rizomáticas.

Músico e pesquisador, Sílvio Ferraz demonstra, com muita pertinência, as dimensões possíveis da escuta contemporânea e advoga em causa de uma escuta múltipla a qual rompe com a estabilidade e o seu confinamento nas formas abstratas e a qual não se limita apenas a um só plano de escuta. Ferraz apresenta as formas possíveis de sensibilidade perceptiva na experiência da música contemporânea, ao propor que, para a realização de uma escuta correspondente aos modos renovados de composição, é preciso uma multiplicidade de escutas que aproxime efetivamente as poéticas da experiência estética.

A "escuta textural", para Ferraz, não se refere à escuta restrita ao material ou à qualidade do material, mas ao devir expressivo do material, demarcando o território que a escuta demarca com o seu ritornelo. Tal textura é definida não pela diferença de grau, mas pela diferença de natureza: ao deslocar um elemento, ao subtrair algo da textura, ela não se torna uma variação do modelo original, mas simplesmente muda de natureza, transforma-se noutra textura ${ }^{5}$. Nesse tipo de escuta das nuanças, o que conta não é a qualidade sonora em si, um atributo preestabelecido, mas do devir expressivo dessa qualidade ao voltar para a escuta sobre a própria percepção que realiza o enunciado sônico. É preciso antes atentar para a escuta da nuança sonora, das texturas e suas potencialidades, não se retendo na mera apresentação de um mero colorido orquestral.

Tal escuta ultra-sensível das nuanças do espectro sonoro nutre-se de suas dobras imperceptíveis, inabarcáveis, dos espaços 
surdos e internos do som. Na heterogeneidade que compõe a autopoiesis da escuta textural, instável e múltipla, o ouvinte passeia por entre os seus espaços e as suas dobras irrepetíveis. A instabilidade da textura está diretamente relacionada com a existência de uma escuta de nuanças, das dobras das texturas não alcançáveis pela abstração. Enreda-se uma espécie de rede complexa em que qualquer ponto de qualquer território toca qualquer ponto de qualquer outro território, como num rizoma.

$\mathrm{Na}$ escuta textural constituem-se os platôs, as estratificações de planos de escuta contemporâneos, que se deixam entrecruzar e se permeiam o tempo todo. Trata-se de uma escuta nômade, que passa incessantemente do detalhe à forma geral. ( ' ) O ouvinte vagueia livremente entre escutas texturais, figurais e gestuais, passando por territórios que são o desdobramento infinitesimal de outros territórios, numa intensa atividade de ligar e desligar elementos ou partículas sonoras. Acorrem, nessa modalidade auditiva, a ressonância, os graus de conectividade, os pontos instáveis de referência, a trama inidentificável de pontos de origem, as linhas de fuga e as múltiplas possibilidades de conexões ${ }^{6}$.

Para Ferraz, mesmo que a multiplicidade de modos composicionais do século $X X$ não garanta uma multiplicidade de escutas correspondentes, é possível encontrar, através da compossibilidade dos modos de escuta heterogêneos, infinitas linhas escapatórias até mesmo em meio aos enunciados sonoros já capturados pelo hábito.

\section{Notas}

1 CAGE, John. Silence.1957, os.116 e 191 passim.

2 CAGE, John. De Segunda a Um Ano. 1967, p. 33.

\section{FERRAZ, Sívio. Música e Repetição. 1996, p. 58.}

4 Oritornelo, segundo a leitura de Ferraz sobre o pensamento de Deleuze, é esse movimento de territorialização realizado por matérias de expressão num determinado sistema, num movimento incessante e irreversível de territorialização, desterritorialização e reteritorialização. Um exemplo de ritornelo, no campo da escuta é o da vibração que se transforma em deviroutro da sensação de vibração até ao ponto em que o objeto se faça no pensamento como som. 0 ritornelo da vibração demarca o território do som.
A vibração cria outro território ao moldar o ouvido interno e externo e encontra outro território no pensamento, na forma de conceitos, perceptos e afectos. Quanto ao ritornelo da escuta musical, músicas diferentes participam na configuração de escutas diferentes e escutas diferentes incidem na configuração de novas musicalidades. FERRAZ, Sílvio. Música e Repetição. 1996, p. 154.

5 "Por textura podemos entender ainda a sensação produzida pela configuração e pelo dinamismo dos elementos presentes num determinado fluxo sonoro. Pode ser vista como o primeiro elemento da percepção musical e, por conseguinte, o último: o resultado da sobreposição de elementos numa composição. Tal qual a cor e a temperatura, a textura é intensiva, não há como subtrair ou dividir uma textura sem que ela mude de natureza." FERRAZ, Sílvio. Música e Repetição. 1996, p. 166.

6 "O ouvinte não apenas ouve um complexo sonoro, mas se torna partícula do tecido sonoro: digamos que o sujeito se transfigura passo a passo com o som, para praticamente percorrer os entremeios desse som." FERRAZ, Sílvio. Música e Repetição. 1996, p. 153

70 compositor Xenakis já dizia que a escuta humana é não-linear, uma escuta hors-temps: a escuta, para ele, se funda na memória, na coexistência dos fragmentos disparatados que não são contemporâneos do ato de percepção. Por isso Xenakis propõe abrir espaço para uma composição que ponha em jogo justamente a desordem e a não-linearidade da percepção humana. Cf. FERRAZ, Silvio. Música e Repetição. 1996, p. 69.

\section{Referências}

ADORNO, Theodor W. O Fetichismo na Música e a Regressão da Audição. In: Os Pensadores. vol XLVIII, São Paulo: Abril Cultural, 1975 .

Perspectiva, 1974

A Filosofia da Nova Música. São Paulo: Ed.

HORKHEIMER, Max. Dialética do Esclarecimento. São Paulo: Ed. Perspectiva, 1977.

BARRAUD, H. Para compreender as músicas de hoje. São Paulo: Ed. Perspectiva, 1975.

Óbvio e Obscuro. Trad. Léa Novaes. Rio de Janeiro: Nova Fronteira, 1990.

BAUMAN, Zygmunt. O Mal-Estar da Pós-Modernidade. Rio de Janeiro: Zahar, 1997. 
BOULEZ, Pierre. A Música Hoje. São Paulo: Ed. Perspectiva, 1972. 1987.

CAGE, John. De Segunda a Um Ano. São Paulo: Ed. Huicitec, 1985.

Hillman Printers, 1987.

Silence - Lectures \& Writtings. Frome, Somerset:

DELEUZE, Gilles. Diferença e Repetição. Trad, Luiz Orlandi e Roberto Machado. Rio de Janeiro: Graal, 1988.

\section{São Paulo: Ed. 34, 1997.}

; GATTARI, Felix. 0 Ritornelo. In: Mil Platôs n. 4 ,

ECO, Umberto. Obra Aberta. Série Debates, São Paulo: Ed. Perspectiva, 1976.

.Tratado Geral de Semiótica. Trad. Antônio de Pádua Danesi e Gilson César Cardoso de Souza, São Paulo: Ed. Perspectiva, 1980.

ENO, Brian; SCHMIDT, Peter. Oblique Strategies. Londres: [s.n.], 1975 ERDMAN, Joan L. The Empty Beat: Khãli as a sign of time. In: American Journal of Semiotics, Vol. 1, N 4, pp. 21-45, Chicago: University of Texas Press, 1982.

FERRAZ, Sílvio. Música e Repetição. São Paulo: Educ, 1998.

GUIMARÃES, César Geraldo. Imagens da Memória: entre 0 legível e o visível. Belo Horizonte: Ed. UFMG, 1997.

HOBSBAWM, Eric. A Era dos Extremos. Rio de Janeiro: Paz e Terra, 1979.

JOURDAIN, Robert. Música, Cérebro e Êxtase: como a música captura nossa imaginação. Rio de Janeiro: Ed. Objetiva, 1998.

MAGNANI, Sérgio. Expressão e Comunicação na Linguagem da Música. Belo Horizonte: Editora UFMG, 1989.

MORAES, J. Jota. Música da Modernidade. São Paulo: Brasiliense, 1983.

PARRET, Herman (org.). A Estética da Comunicação - Além da Pragmática. Campinas: Ed. da Unicamp, 1997.

PEIRCE, C. S. Semiótica e Filosofia. São Paulo: Cultrix, 1993.

PIGNATARI, D. Informação, linguagem, comunicação. São Paulo: Cultrix, 1988.

PINTO, Júlio. 1, 2,3 da Semiótica. Belo Horizonte: Ed. UFMG, 1995.

PLAZA, Julio. Tradução Intersemiótica. São Paulo: Ed. Perspectiva,
ROEDERER, Juan G. Introdução à Física e Psicofísica da Música. São Paulo: Edusp, 1998.

RUSSOLO, Luigi. The Art of Noises. Nova lorque: Pendragon Press, 1986.

SALZMAN, Eric. Introdução à Música do Século XX. Rio de Janeiro: Zahar Editores, 1970.

1SANTAELLA, L. \&NÖTH, W. Imagem: cognição, semiótica, mídia. São Paulo: lluminuras, 1999.

SCHAEFFER, Pierre. Traite des objets musicaux. Paris: Editions du Seuil, 1968.

La Musique Concrète. Paris: Presses Universitaires de France, 1973.

SCHAFER, M. O Ouvido Pensante. São Paulo: Ed. UNESp, 1991.

SHURMMAN, Ernst F. A Música Como Linguagem - Uma abordagem histórica. São Paulo: Brasiliense, 1990.

TAMM, Eric. Brian Eno - His Music and The Vertical Color of Sound. Boston: Faber \& Faber, 1989.

WISNIK, José Miguel. O Som e os Sentidos. São Paulo: Cia das Letras, 1990.

\section{Referências fonográficas}

1906 - Erik Satie: Passacaille (grav. de 1983: P. Maranca, C. C. Arruda, F. Império, A Pinto) - Fermata

1914 - Erik Satie: Choses Vues à Droit et à Gauche (Sans Lunettes) - Fermata

1931 - Edgar Varèse: Ionisation \{001\} - One Way Records

1949 - Pierre Schaeffer e Pierre Henny: Synphonie pour un Homme Seul - Philips

1954 - Edgar Varèse: Déserts - One Way Records

1958 - Edgar Varése: Poème Électronique - One Way Records

1962 - György Ligeti: Volumina für Orgel- Wergo

1966 - Steve Reich: Come Out e lt's Gonna Rain - Nonesuch Records

1967 -György Ligeti: Etüden für Orgel - Wergo 1970 - Kraftwerk: "Kraftwerk" - Capitol 
1973 - Brian Eno e Robert Fripp: No Pussy Footing - Virgin, Opal, Warner

1975 - Brian Eno: Another Green World - Obscure

1975 - Brian Eno: Discreet Music - Obscure

1976 - Jan Steele e John Cage (produtor: Eno): Voices and Instruments - Obscure

1976 - Michael Nyman (produtor:Brian EDneoc)a:y Music Obscure

1977 - Brian Eno, Möebius e Roedelius: Cluster and Eno - Sky

1978 - Brian Eno: Music for Films - Polydor/EG

1978 - Vangelis: Beaubourg - Windham Hill Records

1978 - Brian Eno: Music for Airports I - Polydor / EG Records

1979 - Brian Eno, Möebius e Roedelius: After the Heat - Sky

1980 - Brian Eno e David Byrne: My Life in the Bush of Ghosts EG Records

1980 - Harold Budd e Brian Eno:A mbient \#2: The Plateaux of Mirror .EG Records

1980 - Laraaji (produzido por EAnmob)i:e nt \#3: Day of Radiance. EG Records

1980 - Vol. 2 - EG Records

1982 - Brian Eno: On Land 4 - Polydor/EG

1983 - BrianEno, Daniel Lanois e RogerEno:Apollo-Atmospheres \& Soundtracks - Virgin/ EG Records

1983 - Brian Eno (produzido por Eno e Daniel Lanois) Music for Films, Vol. II. - EG Records

1985 - Brian Eno: Thuesday Afternoon - EG Records

1985 - Brian Eno e Roger Eno: Voices - EG Records

1985 - Cluster (Moebius/Roedelius) e Brian Eno: Old Land Relativity

1991 - The Orb: The Orb's Adventures Beyond the Ultraworld Island Records

1993 - Julio Viera, Fernando López Lezcano, Jorge Rapp,
Guillermo Pozzati, Gustavo Chab, Miguel Angel Calzón, Carlos CeMúsica Electroacústica en la Argentina (Perspectivas 1) - Tarka

1997 - Reich Remixes: Coldcut, Howie B, Andrea Parker, Tranquilit Bass, Mantronik Maximum Drum Formul, Nobukazu Takemura, D* Notes, DJ Spooky, Ken Ishii - Nonesuch Records

1997 - Aphex Twin: Come To Daddy - Warp Records

1999 - Roedelius (Surumu Hirasawa, Kenii Konishi, Alquimia,

David Bickley, Alex Patterson )G:lobal Trotters Project Vol. 1-Drive - Ryko

2000 - William Ørbit: Pieces In A Modern Style - Maverick Records 2001 - Autechre: Confield - Warp Records

\section{Arquivos virtuais -álbuns e faixas acessadas em sites MP3:}

Erik Satie (Piano works, Gymnopédies);

John Cage (Imaginary Landscape n\#1, In a Landscape);

Steve Reich (It's Gonna Rain, Come Out, Piano phase, Clapping Music, Eight Lines, Phase Patterns, Pulses, The Desert Music, Different Trains);

Terry Riley (Poppy Nogood);

Pierre Schaeffer (Etude aux Chemins du Fer, L'oeuvre Musicaleallegro);

Pierre Henry (Marche Du Jeune Homme, Le Voyage - Divinit Plaisibles, Messe pour le Temps Present, Too Fortiche, Teen Tonic, Eau + Machines, Fivre 2);

Olivier Messiaen (Oiseaux exotiques, 1955; Catalogue des oiseaux, Et Expecto Ressurrectionem mortuorum; L'ascension, Les Corps Glorieux, Foullis D'arcs-en-ciel, Pour L'ange, Notre Dame de L'oubli, Trois Petites Liturgies de la Presence Divine, Oraison);

Karlhaenz Stockhausen (Gesang der Junglinge, Ge1, Helicopters, Helikopter Streichquartett, Kontakte Structur 2, Microphonie II, Telemusik, Hymnen);

G. Ligeti (Kammerkonzert, Ramifications, Lux Aeterna, Atmosphères). 